\title{
Field trial with oral vaccination of dogs against rabies in the Philippines

\author{
Roland Estrada ${ }^{1}$, Ad Vos ${ }^{* 2}$, Renato De Leon 3 and Thomas Mueller4
}

Address: ${ }^{1}$ Institute of Veterinary Medicine, DMMMSU, Bacnotan, La Union, Philippines, ${ }^{2}$ IDT GmbH, PSF214, o6855 Rosslau, Germany, 3Provincial Veterinary Office, San Fernando City, La Union, Philippines and 4Federal Research Centre for Virus Diseases of Animals, 16868 Wusterhausen, Germany

E-mail: Roland Estrada - ovd_philippines@pinoyjustice.com; Ad Vos* - ad.vos@idt-direct.de; Renato De Leon - rcdeleon@thepentagon.com; Thomas Mueller - thomas.mueller@wus.bfav.de

*Corresponding author

Published: 28 November 2001

BMC Infectious Diseases 200I, 1:23
Received: 12 October $200 \mid$

Accepted: 28 November 2001

This article is available from: http://www.biomedcentral.com/I47I-2334/I/23

(C) 200 I Estrada et al; licensee BioMed Central Ltd. Verbatim copying and redistribution of this article are permitted in any medium for any non-commercial purpose, provided this notice is preserved along with the article's original URL. For commercial use, contact info@biomedcentral.com

\begin{abstract}
Background: The potential role of oral vaccination of dogs against rabies in the Philippines was investigated in terms of safety and efficacy.

Methods: Prior to the vaccination campaign, a house-to-house survey was carried out to collect data on the dog population in the study area, the coastal village of Mindoro. During the vaccination campaign all households were visited again, and all dogs encountered ( $>2$ months old) were, if possible, vaccinated. Furthermore, 14 dogs vaccinated were bled on different occasions.

Results: During the survey, a total of 216 dogs were counted, and none of these animals had previously been vaccinated against rabies. Only 17 dogs could be restrained and subsequently vaccinated directly by the vaccinators. Another 126 dogs were offered a local-made boiled intestine bait, containing a capsule filled with $3.0 \mathrm{ml} \mathrm{SAD} \mathrm{BI9}\left(10^{7.9} \mathrm{FFU} / \mathrm{ml}\right)$. The bait acceptance rate of dogs offered a bait was $96.1 \%$. The vaccination coverage of the dog population (> 2 months old) estimated by the number of animals vaccinated directly and the number of dogs that accepted a bait and subsequently punctured the vaccine container was $76 \%$. Fifteen and 29 days after the vaccination campaign 6 and 10 dogs $(n=14)$ had rabies virus neutralizing antibody titres of $\geq 0.5$ $\mathrm{IU} / \mathrm{ml}$, respectively. No unintentional contacts of nontarget species, including humans, with the vaccine virus were reported.
\end{abstract}

Conclusions: The results of the campaign show that oral vaccination of dogs against rabies is a promising supplementary method in dog rabies control in the Philippines.

\section{Background}

The number of human deaths due to rabies is estimated between 40,000 and 60,000 annually [1], $98 \%$ of these cases are attributable to the bite of a rabid dog [2]. Although significant progress in dog rabies control has been reported from many countries, in others little or no progress is made. Partly, because a large segment of the dog population is not accessible for traditional vaccination by the parenteral route. For these countries oral vaccination of dogs (OVD) has been proposed as a supplementary policy to parenteral vaccination, in the hope of increasing the overall vaccination coverage of the 
dog population involved. Oral vaccination programmes have been successful in eradicating wildlife rabies in large areas of Europe and North-America [3-5].

In recent years, the World Health Organization (WHO) has provided general guidelines that include planning and organization of field trials with OVD [6]. OVD field trials have been conducted in Turkey, South Africa, Sri Lanka and Thailand [1]. The responsible authorities in the Philippines have also been interested in this novel technique. Here, dog rabies is widely distributed and application of traditional control measures have yielded less than optimal results. While the Philippines qualified for the use of OVD as described by the WHO criteria [6], it was decided to conduct a field trial. The first steps for implementing OVD projects are; to select a candidate vaccine, to test its safety and efficacy, to select a bait well accepted by the local dog population, and to evaluate bait-uptake in the target population. Thus, prior to this field trial, the safety and efficacy of the vaccine virus candidate was tested in target and nontarget species (Estrada, unpublished results), and a bait made from cheap locally available material was identified and tested under field conditions [7]. It was decided to use a bait delivery system that maximizes bait-availability to the target population, meanwhile minimizing the possibilities of contact with the vaccine virus and/or vaccine baits by nontarget species, especially humans. This system, going house-to-house and offering a bait to every free-roaming or restricted dog encountered that is not accessible for parenteral vaccination, was developed and tested in Turkey $[8,9]$.

Although no standard protocol for OVD field trials is presently available, it was decided to incorporate as many suggestions on OVD field trials made by WHO as possible. Thus, the trial included data collection on dog biology (dog density, population structure and dog : human ratio), bait distribution (training of personnel, bait delivery system, costs of baits, acceptance by local human populations), risk assessment (possible exposure of nontarget species to baits), and efficacy (vaccination coverage) [10]. The protocol of the OVD-trial has received approval of all regulatory and other local and national authorities in the Philippines concerned. Furthermore, prior to the field trial the active support of the local community and - authorities was guaranteed.

\section{Study area}

Mindoro is part of the municipality of the city of Bangar, in the northern part of the province La Union, Philippines (Figure 1). The village is situated at the coast of the Chinese Sea in the estuary of the Amburayan river. It was decided to conduct this field trial shortly before the rainy season. Due to the rain, the riverbed of the Amburayan

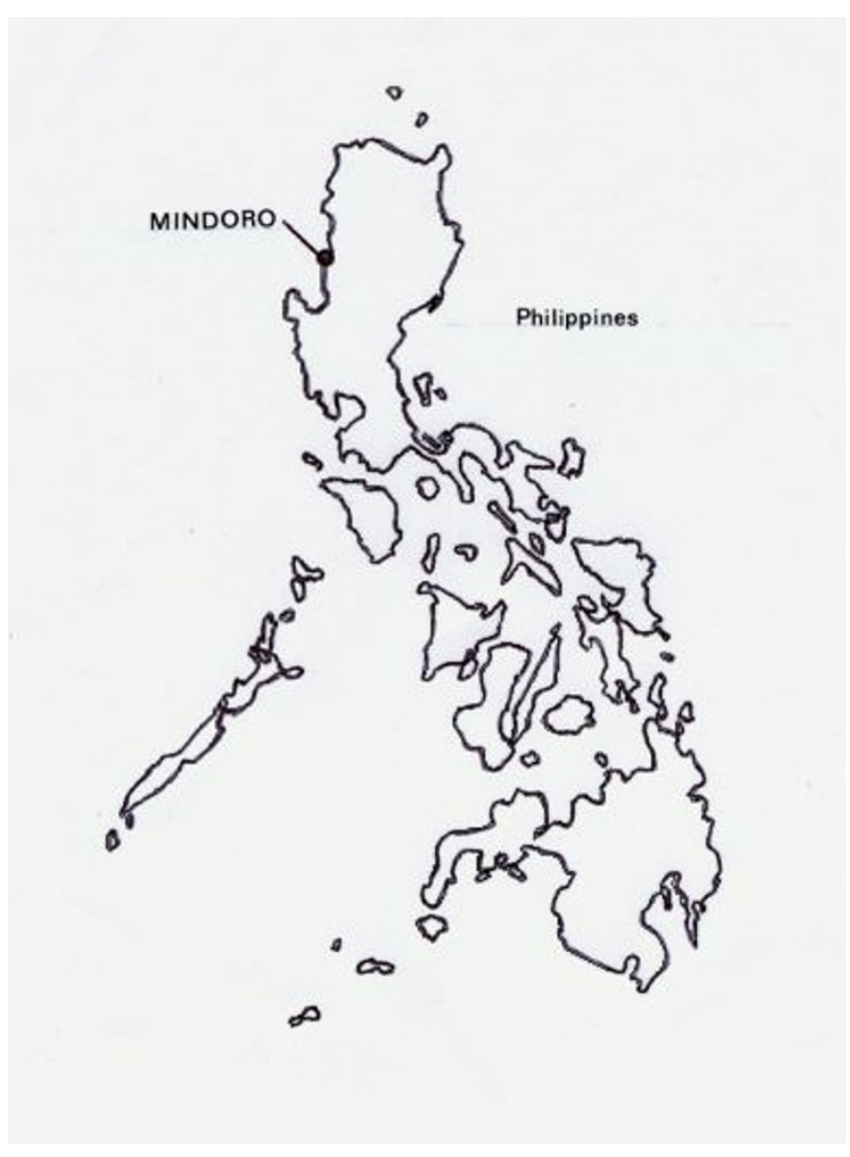

Figure I

Location of Mindoro, La Union, in the Philippines, where the first oral vaccination campaign was conducted.

river will be flooded and the island will be completely isolated from the mainland. Thus, the river and the sea will act as a kind of safety barrier. According to a census conducted in 2000, the total human population of Mindoro was 1480, divided over 304 households. Since 1995, no rabies case has been reported from Mindoro itself. However, rabies is endemic in the province of La Union. In this area, 23 dogs and 1 human were reported rabies positive during the first three months of 2001.

\section{Materials and Methods Dog population}

Fortunately, there were no ownerless dogs in Mindoro, so complicated mark-recapture models to estimate dog population size were not necessary, a simple house-tohouse survey was sufficient. Information was gathered on the following subjects; number of dogs and humans, level of supervision, age and sex of dogs, vaccination status. 


\section{Vaccine baits}

The WHO Collaborating Centre for Rabies Surveillance and Research in Tübingen, Germany, introduced the oral rabies vaccine virus SAD B19 as a possible candidate for OVD [11]. The SAD B19 vaccine virus is a derivative of the original SAD virus (Street-Alabama-Dufferin). The latter was isolated from a rabid dog in 1935 in Alabama, USA, and after passaging adapted to Baby-Hamster-Kidney (BHK) 21 cells $[12,13]$. SAD B19 is globally the most widely used oral rabies vaccine virus; since 1983 more than 100 million SAD B19 vaccine baits have been distributed in more than 15 countries [14]. During intensive laboratory - and field trials, the feasibility of OVD with SAD B19 has been tested and proven in Turkey $\left[8,11,15^{-}\right.$ $20]$. The vaccine container $( \pm 6.5 \times 3.0 \times 0.7 \mathrm{~cm})$, a polyvinyl chloride capsule with serrated edges and sealed with an aluminium cover foil, contained $3 \mathrm{ml} \mathrm{SAD} \mathrm{B19}$ (107.9 Foci Formatting Units [FFU] /ml). The capsules were slid into the baits; boiled sections of the large intestine of pigs [7]. The acceptability of these baits have been assessed during previous bait trials in the Philippines; $98 \%$ of all dogs accepted the bait without hesitation [7].

\section{Vaccination campaign}

Eight vaccination teams, consisting out of two persons each, visited all households. Every $\operatorname{dog}(>2$ months of age) encountered that could not be handled by the vaccinators and/or owners was offered a bait by one of the vaccinators after obtaining informed consent from the owner. Afterwards, if possible, the discarded vaccine container was collected by a vaccinator wearing examination gloves and who had received rabies pre-exposure treatment. The vaccine baits were kept in a cool box. The result of the vaccination attempt was recorded, together with the name of the owner.

To assess the vaccination coverage, blood samples were taken from a number of dogs prior to and on the day of the campaign and from the animals on two occasions afterwards (15 and 29 days post vaccination). Virus neutralizing antibodies (VNA) titres were determined by the rapid fluorescence focus inhibition test (RFFIT) [21], with the modifications of that method as described by Cox and Schneider [22]. The titres were converted to International Units (IU/ml). In this study, dogs with titres of $\geq 0.5 \mathrm{IU} / \mathrm{ml}$ were considered immune and protected against rabies infection.

\section{Risk assessment}

Dogs are very closely associated with humans, therefore safety requirements are more stringent for OVD than for oral vaccination of wildlife [23]. To assess the safety of the field trial the following parameters have been used: (1) the absence of vaccine virus induced rabies in target and nontarget species, and (2) the absence of human ex- posure to the vaccine baits and - virus. Prior to the campaign, all appropriate local officials (including public health officials and teachers) were informed in detail. Furthermore, advice aiming at avoiding contacts between freshly vaccinated dogs and humans (esp. children) was given to the household members present during the vaccination attempt. They were also told, not to pick up (discarded) vaccine containers not recollected. If people would somehow come in contact accidentally with the vaccine virus they should report this to the local officials. Two days after the vaccination campaign Mindoro was visited again and the local officials were interviewed if people had reported contacts with freshly vaccinated dogs or if any adverse reaction in the vaccinated animals had been observed.

To detect possible vaccine virus induced rabies in dogs or other nontarget species, it was decided to collect as many animals as possible that showed signs of illness or died during a period of three months post vaccination campaign. Afterwards the brain of these animals, if possible, were examined for viral antigen by the fluorescence antibody test (FAT) [24].

\section{Results \\ Dog population}

The dog : human ratio was 1 : 6.9. 121 (39.8\%) of 304 households claimed to own one or more dogs. A total of 216 animals were counted; 175 animals older than 2 months and 41 puppies ( $\leq 2$ months). An estimation of the dog density can not be given, while the area that is utilized by the dogs changed in time, due to changing water levels. However, activities of the dogs were largely restricted to the village and its direct surroundings. The overall sex ratio was significantly biased towards females; $1: 1.72$ (male : female); $\chi^{2}=11.61$, $\mathrm{df}=1, \mathrm{n}=158$, $\mathrm{P}<0.001$. Of the 48 adult dogs present $(\geq 1$ year old), only 4 animals were males. However, the sex ratio of dogs less than one year did not differ significantly from unity; $1: 1.02$ (male : female). The average age of the male $(n=50)$ and female $(n=90)$ dogs was $0.4 \pm 0.6$ and $1.7 \pm 2.2$ years, respectively. $66 \%$ of the dogs were aged less than one year old. These figures indicate a very high 'disappearance-rate', especially among the males. No ownerless dogs were observed. Furthermore, according to the owners none of the dogs had been previously vaccinated against rabies and all dogs were unrestricted. Most dogs originated from Mindoro, but $17.6 \%$ of the animals were imported from other areas, including rabiesinfected areas. Dogs were generally in a very poor condition; only a few animals did not show clinical symptoms of sarcoptic mange. 


\section{Vaccination-campaign}

The 41 puppies ( $\leq 2$ months old) were too young to be vaccinated, thus 175 dogs were eligible for vaccination. To assess the efficiency of the oral vaccination campaign, it was necessary to estimate the numbers of animals that could be vaccinated by the parenteral route. Only 9.7\% (n $=17$ ) of these 175 dogs could be caught and restrained by the vaccinators without much problems. However, the dog owners refused to assist and constrain these animals, afraid to be bitten. All these animals were between 2-4 months old. These 17 dogs were however not vaccinated by the parenteral route but were vaccinated by direct instillation of the vaccine virus into the mouth cavity, in order to make sure that enough serological data of orally vaccinated dogs could be collected.

Of the remaining 158 dogs 126 animals could be relocated and were offered a bait. The animals offered a bait were not marked individually, therefore three dogs were accidentally offered a bait twice. Of the 129 oral vaccination attempts, only 5 dogs ran away or refused the bait; indicating an overall bait acceptance of 96.1\%. Another four dogs accepted the bait, but walked away with it, so the fate of the bait could not be recorded and subsequently the (discarded) vaccine container could not be recollected. Four dogs swallowed the bait immediately, hence it was presumed that the vaccine container was not punctured. These dogs were therefore not considered vaccinated. Another 13 dogs swallowed the vaccine container after prolonged chewing and it was assumed that the vaccine virus was released into the oral cavity. The remaining 103 dogs accepted the bait and discarded the punctured vaccine container afterwards. No dog discarded a vaccine container that had not been punctured.

An estimation of the overall vaccination coverage achieved during this field trial of dogs eligible for vaccination (more than 2 months of age) was $76 \%$, based on the number of animals that accepted the bait and subsequently punctured the vaccine container $(n=116)$ or were vaccinated by direct oral instillation $(n=17)$. The vaccination coverage of the dog population, including the puppies, was estimated at $61.6 \%$.

Prior to and on the day of the vaccination campaign, blood samples (BO) were collected from 14 animals; 12 samples from dogs offered a bait and 2 from animals vaccinated by direct administration of the vaccine virus into the mouth cavity. All but two dogs tested negative $(<0.5$ $\mathrm{IU} / \mathrm{ml}$ ) for rabies VNA prior to the vaccination campaign (geometric mean titre $[\mathrm{GMT}]=0.10 \mathrm{IU} / \mathrm{ml}, \mathrm{s} . \mathrm{d} .=0.34$, $\mathrm{n}=14$ ). The individual titres of the dogs were; 0.01, 0.03, 0.03, 0.04, 0.06, 0.06, 0.08, 0.10, 0.10, 0.11, 0.28, 0.29, 0.64 and $1.25 \mathrm{IU} / \mathrm{ml}$. Fifteen and 29 days after the vaccination campaign, subsequent blood samples could only be collected from 8 of these 14 dogs. Several dogs perished as a direct or indirect result of a typhoon that hit the island 10 days after the campaign. Also, the owners of other dogs were not able to relocate or restrain their dogs, or simply refused to have their dog bled again. Therefore, an additional six dogs were selected, so a total of 14 animals were bled on all three occasions. Six and 10 of $14 \mathrm{dogs}$ had VNA titres $\geq 0.5 \mathrm{IU} / \mathrm{ml} 15$ and 29 days post vaccination, respectively. The individual titres of the dogs bled 15 days post vaccination were $0.05,0.05,0.07$ (direct), 0.10, 0.13, 0.15, 0.15, 0.36, 0.50, 2.90, 3.93, $5.65,8.28$ and $24.60 \mathrm{IU} / \mathrm{ml}(\mathrm{GMT}=0.53$, s.d. $=6.64)$. The titres of the dogs sampled 29 days post vaccination were $0.21,0.23,0.24,0.35,0.57,1.08,5.20$ (direct), 5.61 (direct), 6.94, 13.12 (direct), 18.39, 26.86, 103.86 and $166.90 \mathrm{IU} / \mathrm{ml}(\mathrm{GMT}=3.58$, s.d. $=49.03)$.

\section{Risk assessment}

No adverse reactions in dogs offered a bait or vaccinated by direct oral instillation were reported from their owners. Also, no deaths in other nontarget species (cat, chicken, pig, rats) were reported. Unfortunately, only three dogs, showing signs of illness, were collected and examined for the presence of rabies virus; all animals tested negative (FAT). Also, no human contacts with the vaccine virus, direct or indirect, were reported.

\section{Discussion}

At the moment the only available method to control dog rabies effectively is vaccination. For this purpose, a large proportion of the dog population ( $75 \%$ or more) needs to be immunised in order to interrupt the transmission cycle within the population [1,25]. Unfortunately, many dogs are inaccessible for vaccination by the parenteral route in the Philippines. Evaluation of a mass parenteral vaccination campaign in Sorsogon Province, Philippines, indicated that between $47.4 \%$ and $75 \%$ of the dogs were vaccinated, depending on the estimation technique used [10]. In Mindoro, only $9.7 \%$ of the dogs could be handled by the vaccinators without much trouble. Of course, the number of dogs that can not be vaccinated by the parenteral route within a population is variable, depending, among others, on the skills of the vaccinators to restrain the animals. Oral vaccination appears to offer a new perspective in dog rabies control. In Sri Lanka, the maximum vaccination coverage achieved through parenteral vaccination and stray dog removal campaigns was $60 \%$. The vaccination coverage was increased to $72 \%$ by use of supplementary oral vaccination [26]. In Kusadasi, Turkey, 59\% of all free-roaming dogs could not be vaccinated by the parenteral route, but were accessible for oral vaccination [8]. Oral vaccination will not only increase the total number of dogs vaccinated, but also the time-efficiency is greatly improved; offering a bait and informing the dog owners will only take a fraction of the 
time needed to catch, constrain and vaccinate by the parenteral route the often free-roaming dogs. For example, during a mass vaccination campaign in Metro Manila, Philippines, total person minutes spent per dog, accessible for parenteral vaccination, was 13.96 minutes [10].

In terms of efficacy of OVD field trials the primary indicator of success is the vaccination coverage achieved [6]. During this field trial, $96.1 \%$ of the dog population aged 2 months or older accepted the bait without hesitation. The high acceptance rate achieved was mainly a result of the attractiveness of the bait used. Baits were quickly taken up and most were rapidly and completely consumed by the dogs. The advantage of a local-made bait versus an imported manufactured bait are manifold. The chances that dogs will not accept a bait, will increase with growing unfamiliarity with the bait (texture, odour and taste). Thus, baits made from local material have a considerable advantage over imported manufactured baits. In a field trial in Tunisia, only $44 \%$ of the free-roaming owned dogs accepted a manufactured bait completely or partially [27]. Another important advantage using localmade baits are the costs; the price of the bait material used in this trial was only U\$0.01 [7]. Thus vaccine-baits made from cheap material that is locally available will reduce the overall costs of OVD considerably compared to imported manufactured vaccine baits. One should not forget that a major obstacle for effective rabies control in most countries with dog-mediated rabies are the limited financial resources available for rabies control. Thus, the cost-effectiveness of OVD will therefore be a decisive factor for the feasibility of this novel approach.

However, to evaluate the efficacy of the field trial, the estimated vaccination coverage based on the proportion of animals accepting the bait is not sufficient. A more sensitive method is the seroconversion rate of the dogs vaccinated. Although, the seroconversion rate is closely linked with bait-uptake, the seroconversion rate is in most cases lower than bait-uptake; e.g. a dog can separate the vaccine container from the bait, or the vaccine container is swallowed before it was punctured, so in both cases no vaccine virus is released into the mouth cavity.

In Mindoro, only 6 of 14 dogs had developed VNA liters $\geq 0.5 \mathrm{IU} / \mathrm{ml} 15$ days post-vaccination, two weeks later already 10 of 14 dogs had seroconverted above this threshold. These serology results underscore the high immunogenicity of SAD B19 [28]. Another live-modified virus yielded much lower seroconversion rates; only 6 of 31 orally vaccinated laboratory beagles developed a titre of $\geq 0.5 \mathrm{IU} / \mathrm{ml}$ [29]. In a more recent study, 4 of 12 laboratory dogs, vaccinated orally with a vaccine bait con- taining this other oral rabies vaccine candidate, developed VNA within 4 weeks post-vaccination. Unfortunately, the antibodies did not persist very long, 4 weeks post vaccination none of the animals had any detectable VNA ( $\geq 0.1 \mathrm{IU} / \mathrm{ml})[30]$. However, the concept of the arbitrarily defined threshold ( $\geq 0.5 \mathrm{IU} / \mathrm{ml}$ ) has been questioned by several authors, since vaccinated dogs without VNA, or well below this threshold, survived a subsequent rabies challenge $[29,30]$. It seems that only cell-mediated immunity parameters correlate with protection induced by rabies vaccination [31]. Although during a recent study in foxes, it was shown that all vaccinated animals that developed titres of $\geq 0.5 \mathrm{IU} / \mathrm{ml}$ survived a challenge, whereas all vaccinated foxes with titers $<0.5$ $\mathrm{IU} / \mathrm{ml}$ succumbed to rabies [32]. The absence of detectable VNA can also indicate a vaccination failure. It is a well known fact that malnourished dogs suffering from nutritional deficiencies or animals with concurrent infections or illnesses, like the dogs in Mindoro, can respond sub optimally to vaccination [33,34]. Experimental and field studies clearly showed that it was more difficult to elicit an immune response and subsequently achieve protection in indigenous dogs in developing countries after oral vaccination than in laboratory dogs $[11,16,35]$. However, 5 of 6 local Turkish dogs offered a boiled intestine bait, containing a SAD B19 filled vaccine container, seroconverted $(\geq 0.5 \mathrm{IU} / \mathrm{ml})$, and were subsequently protected against rabies [36].

Although OVD was suggested as a supplementary technique to traditional parenteral vaccination, it seems that in areas like Mindoro where all dogs are unrestricted and only few animals are accessible for parenteral vaccination (within reasonable time and effort), it is more efficient to use only oral vaccination. However, it should be borne in mind that what is suitable for one country, may not necessarily be most appropriate for another [10]. In other countries, parenteral vaccination remains the core of dog rabies control.

Unfortunately, the achieved vaccination coverage will dimimish rapidly, due to the high population turnover. The proportion of dogs less than 1 year of age (66\%) in Mindoro was extremely high. For example, Matter et al [37] observed that only $22 \%$ of the owned dogs were less than 1 year old in Banarli, a rural village in Turkey. Hence, it may be necessary to conduct a vaccination campaign every six months, in order to sustain the high vaccination coverage attained. The high population turnover observed is not surprising considering the extremely biased sex ratio towards females. This is rather unusual, most surveys indicate a surplus of male dogs [38-42]. 
No vaccine virus induced rabies case was reported in the target - and nontarget species. However, only few animals were collected for examination. The major reason for this was a typhoon that hit the area approximately ten days after the campaign. The village had to be evacuated and the typhoon caused a lot of human suffering and material damage. Thus, after returning to the village the people were occupied with more important matters than collecting samples and became increasingly hostile and reluctant to cooperate; e.g. increasing demands for financial compensation for dogs handed over for rabies diagnosis. The three dogs examined were all emaciated, and two of them were diagnosed with acute respiratory distress, possibly a result of the typhoon(s).

There was no reported case of human contact to the baits and/or vaccine. The most obvious scenario is the direct contact of a person through handling of a vaccine bait. Exposure may also occur indirectly through contact with a freshly vaccinated dog. Complementary excretion studies with swabbing at regular and frequent intervals after vaccine instillation in local dogs, as suggested by the WHO [6], were carried out during a previous experimental study at Don Mariano Marcos Memorial State University (DMMMSU); it was shown that after 60 minutes no vaccine virus was detectable anymore in the saliva (Estrada, unpublished results). The chances of unintentional exposure of the vaccine virus to nontarget species, especially humans, was further limited by the recollection of baits not accepted and the discarded vaccine containers. The absence of human contacts with the vaccine virus is closely linked with the bait delivery system used. Several other systems have been suggested; bait deposition at selected sites (similar to oral vaccination of wildlife), or bait distribution to dog owners [27,43]. To reach an acceptable vaccination coverage with the first system would mean distributing an unrealistic number of thousands of baits per km²[19,27,44], also the number of unintentional contacts of nontarget species (bait competitors), including humans, will be unacceptable high. In Istanbul, Turkey, 55.3\% and $33.3 \%$ of baits placed at selected sites were taken by nontarget species during day-time and the evening, respectively [19]. Distribution of baits to dog owners was also not considered suitable by the authors, due to the increased risks of human contacts with the vaccine virus. Ben Youssuf et al. reported 25 unprotected human contacts during a field trial with placebo vaccine baits in Tunisia; $1.7 \%$ of the total human population in the study-area [25].

\section{Conclusions}

The bait delivery system using baits made from cheap locally available material can be considered safe, effective and cost-beneficial. A high vaccination coverage (76\%) as indicated by bait-acceptance was achieved among the local dog population eligible for rabies vaccination. One month post-vaccination, $71 \%(\mathrm{~m}=14)$ of the dogs vaccinated had virus neutralizing antibody titres of $\geq 0.5 \mathrm{IU} /$ $\mathrm{ml}$. In terms of safety, no target and nontarget species exposure to the vaccine virus was reported. Thus, the results of this first field trial indicate that oral vaccination may be an effective tool in rabies control in the Philippines.

\section{Competing interests}

The vaccine virus used, is produced by IDT GmbH, Germany. One of the authors is an employee of this company. Furthermore, the leading scientist of this study, Dr. Roland Estrada, has received several training courses abroad in the framework of this study. These were co-financed by IDT GmbH.

\section{Acknowledgements}

First of all, we are very grateful to the members of National Rabies Committee and its Chairman, Dr. Atienza, for their support during the planning and implementation of this field trial. Also, the collaboration with the local authorities of Mindoro was much appreciated. Furthermore, we have to thank Jeanette Burow, Astrid Schameitat and Thomas Selhorst for their assistance during the evaluation of the blood samples at Federal Research Centre for Virus Diseases of Animals, Wusterhausen, Germany. Finally, we have to express our gratitude to all the students of DMMMSU, Institute of Veterinary Medicine, who enthusiastically accompanied us to Mindoro on several occasions to assist us during all stages of the field trial.

\section{References}

I. Meslin FX, Miles MA, Vexenat A, Gemmell MA: Zoonoses Control in dogs. In: Dogs, Zoonoses and Public Health. (Edited by MacPherson CNL, Meslin FX, Wandeler Al) Wallingford, CABI Publishing 2000333-372

2. Fekadu M: Canine rabies. In: The Natural History of Rabies, 2nd Edition (Edited by Baer GM) Boca Raton, CRC Press 1991367-378

3. Stöhr K, Meslin F-X: Progress and setbacks in the oral immunisation of foxes against rabies in Europe. Vet Rec I996, I 39:32-35

4. Müller T, Schlüter $\mathrm{H}$ : Oral immunization of red foxes (Vulpes vulpes L) in Europe: A review. J Etlik Vet Microbiol 1998, 9:35-59

5. Macinnes CD, Smith SM, Tinline RR, Ayers NR, Bachmann P, Ball DGA, Calder LA, Crosgrey SJ, Fielding C, Hauschildt P, et al: Elimination of rabies from red foxes in eastern Ontario. J Wildi Dis 200I, 37:II9-132

6. World Health Organization: Field application of oral rabies vaccines for dogs. World Health Organization, Geneva, 20-22 July 1998. Geneva 1998

7. Estrada RQ, Vos AC, De Leon RC: Acceptability of local-made baits for oral vaccination of dogs against rabies in the Philippines. BMC Inf Dis 200I, I:19

8. Güzel N, Leloglu N, Vos A: Evaluation of a vaccination campaign of dogs against rabies, including oral vaccination, in Kusadasi, Turkey. J Etlik Vet Microbiol 1998, 9:121-134

9. Vos A, Aylan O: Oral immunization of dogs against rabies in Turkey. Inf Circ - WHO Mediterr Zoon Control Cent 1999, 47:I 3-I 5

10. World Health Organization: Report of the fifth consultation on oral immunization of dogs against rabies, Geneva, 20-22 June 1994. Geneva 1994

II. Müller W, Güzel T, Aylan O, Kaya C, Cox J, Schneider L: The feasibility of oral vaccination of dogs in Turkey - an European Union supported project. J Etlik Vet Microbiol I998, 9:6 I-7I

12. Blancou J, Meslin F-X: Modified live-virus rabies vaccines for oral immunization of carnivores. In: Laboratory techniques in rabies, 4th edition (Edited by Meslin FX, Kaplan MM, Koprowski H) Geneva, World Health Organization, 1996324-337

13. Schneider LG, Cox JH: Ein Feldversuch zur oralen Immunisierung von Füchsen gegen die Tollwut in der Bundesrepublik Deutschland. I. Unschädlichkeit, Wirksamkeit und Stabilität der Vakzine SAD B I9. Tierärztl Umschau I 983, 38:3 I5-324 
14. Vos A, Müller T, Schuster P, Schlüter H, Neubert A: Oral vaccination of foxes against rabies with SAD B 19 in Europe, 19831998: A review. Vet Bull 2000, 70:1-5

15. Aylan O: Safety tests of SAD BI9 in Turkish dogs. J Etlik Vet Microbiol I 998, 9:113-119

16. Aylan O, Vos A: Efficacy studies with SAD B I 9 in Turkish dogs. J Etlik Vet Microbiol I998, 9:93-10 I

17. Güzel T, Aylan O, Vos A: Innocuity tests of SAD B I 9 in Turkish nontarget species. J Etlik Vet Microbiol 1998, 9:103-1 I2

18. Schuster P, Gülsen N, Neubert A, Vos A: Field trials evaluating bait uptake by an urban dog population in Turkey. J Etlik Vet Microbiol | 998, 9:73-8|

19. Vos A, Sanli S: Evaluation of a bait delivery system for oral vaccination of dogs against rabies in Turkey. J Etlik Vet Microbiol |998, 9:83-9|

20. Vos A, Neubert A, Aylan O, Schuster P, Pommerening E, Müller T, Chai Chivatsi D: An update on safety studies of SAD B I 9 rabies virus vaccine in target and non-target species. Epidem Infect 1999, I 23:165-175

21. Smith JS, Yager PA, Baer GM: A rapid reproducible test for determining rabies neutralizing antibody. Bull World Health Organz | 973, 48:535-54|

22. Cox JH, Schneider LG: Prophylactic immunization of humans against rabies by intradermal inoculation of human diploid cell culture vaccine. J Clin Microbiol 1976, 3:96- I0I

23. Wandeler AI, Bingham J: Dogs and Rabies. In: Dogs, Zoonoses and Public Health. (Edited by MacPherson CNL, Meslin FX, Wandeler Al) Wallingford, CABI Publishing 200063-90

24. Dean DJ, Abelseth MK, Athanasiu P P: The fluorescence antibody test. In: Laboratory techniques in rabies, 4 edition (Edited by Meslin FX, Kaplan MM, Koprowski H) Geneva, World Health Organization, 19968893

25. Ben Youssef $\mathrm{S}$, Matter HC, Schumacher $\mathrm{CL}$, Kharmachi $\mathrm{H}$, Jemli J, Mrabet L, Gharbi M, Hammami S, ElHicheri K, Aubert MFA, et al: Field evaluation of a dog owner, participation-based, bait delivery system for the oral immunization of dogs against rabies in Tunesia. Am J Trop Med Hyg 1998, 58:835-845

26. Harischandra PAI: Increasing dog vaccination coverage in Sri Lanka: Is oral vaccination the answer? In: Fourth International Symposium on Rabies Control in Asia, 5-9 March 200I, Hanoi, Vietnam. Abstract Book, 2001117

27. Matter HC, Schumacher CL, Kharmachi H, Hammami S, Tlatli A, Jemli J, Mrabet L, Meslin FX, Aubert MFA, Neuenschwander BE, et al: Field evaluation of two bait delivery systems for the oral immunization of dogs against rabies in Tunisia. Vaccine 1998, 16:657665

28. Neubert A, Schuster P, Tüller M, Vos A, Pommerening E: Immunogenicity and Efficacy of the Oral Rabies Vaccine SAD B I 9 in Foxes. J Vet Med B 200I, 49:I79-183

29. Rupprecht CE, Shaddock JS, Sanderlin DW, Hanlon CA, Niezgoda M, Schumacher CL: Oral Rabies Vaccination of Dogs. IsraelJ Vet Med 1998, 34:228-239

30. Orciari L, Niezgoda M, Hanlon CA, Shaddock JH, Sanderlin DW, Yager PA, Rupprecht CE: Rapid clearance of SAG-2 rabies virus from dogs after oral vaccination. Vaccine 200I, 19:45। I-45।8

31. Zanettti CR, De Franco MT, Vassao RC, Pereira CA, Pereira OAC: Failure of protection induced by a Brazilian vaccine against Brazilian wild rabies viruses. Arch Virol 1998, I43:1745-1756

32. Müller TF, Schuster P, Vos AC, Selhorst T, Wenzel UD, Neubert AM: Effect of maternal immunity on the immune response to oral vaccination against rabies in young foxes. $\mathrm{Am} J$ Vet Res 200I, 62:1154-1158

33. Ford RB: Vaccines and vaccination. Issues for the 2 I st century. Suppl Compend Contin Educ Pract. Vet 1998, 20:19-24

34. Robinson RA: Zoonoses and immunosuppressed populations. In: Dogs, Zoonoses and Public Health (Edited by MacPherson CNL, Meslin FX, Wandeler Al) Wallingford, CABI Publishing 2000273-298

35. Schumacher CL, Bishop G, Bingham J, Hammami S, Chaparro F, Von Teichman BF, Aubert MFA, Cliquet F, Aubert A: Protection, seroconversion and safety results of SAG2 in indigenous and laboratory dogs. In: Abstracts IX International Meeting on Research Advances and Rabies Control in the Americas, December 8-I 2, Puerto Vallarta, Mexico 199843-44

36. Aylan O, Vos A: Efficacy of oral rabies vaccine baits in indigenous Turkish dogs. Inf Dis Rev 2000, 2:74-77
37. Matter H, Fico R, Neuenschwander BE: Study of the structure and density of a dog population in Tekirdag (Turkey). J Etlik Vet Microbiol 1998, 9:9-24

38. Beck AM: The ecology of stray dogs: a study of free-ranging urban animals. Baltimore, York Press 1973

39. Daniels T], Bekoff M: Population and social biology of free-ranging dogs, Canis familiaris. J Mamm 1989, 70:754-762

40. Vos A, Turan B: Study of the dog population in Istanbul, Turkey. IEtlik Vet Microbiol 1998, 9:25-34

4l. Matter HC, Daniels TJ: Dog ecology and population biology. In: Dogs, Zoonoses and Public Health. (Edited by MacPherson CNL, Meslin FX, Wandeler Al) Wallingford, CABI Publishing 2000I7-62

42. Pal SK: Population ecology of free-ranging urban dogs in West Bengal, India. Acta Theriol 200I, 46:69-78

43. Linhart SB: Bait formulation and distribution for oral rabies vaccination of domestic dogs: an overview. Onderstepoort J Vet Res 1993, 60:479-490

44. Gleixner $\mathrm{A}$, Meyer $\mathrm{H}$, Aylan $\mathrm{O}$, Vos $\mathrm{A}$ : The delivery of baits to dogs: clenbuterol as baitmarker.J Etlik Vet Microbiol 1998, 9:1 35 142
Publish with BioMed Central and every scientist can read your work free of charge

"BioMedcentral will be the most significant development for disseminating the results of biomedical research in our lifetime."

Paul Nurse, Director-General, Imperial Cancer Research Fund

Publish with BMC and your research papers will be:

- available free of charge to the entire biomedical community

- peer reviewed and published immediately upon acceptance

- cited in PubMed and archived on PubMed Central

- yours - you keep the copyright 